GA-A24076

\title{
APPLICATIONS OF NEW TECHNOLOGY FOR PRODUCTION OF HIGH POWER MILLIMETER WAVES TO MAGNETIC FUSION RESEARCH \\ by \\ J. LOHR
}




\section{DISCLAIMER}

This report was prepared as an account of work sponsored by an agency of the United States Government. Neither the United States Government nor any agency thereof, nor any of their employees, makes any warranty, express or implied, or assumes any legal liability or responsibility for the accuracy, completeness, or usefulness of any information, apparatus, product, or process disclosed, or represents that its use would not infringe privately owned rights. Reference herein to any specific commercial product, process, or service by trade name, trademark, manufacturer, or otherwise, does not necessarily constitute or imply its endorsement, recommendation, or favoring by the United States Government or any agency thereof. The views and opinions of authors expressed herein do not necessarily state or reflect those of the United States Government or any agency thereof. 


\title{
APPLICATIONS OF NEW TECHNOLOGY FOR PRODUCTION OF HIGH POWER MILLIMETER WAVES TO MAGNETIC FUSION RESEARCH

\author{
by \\ J. LOHR
}

This is a preprint of an invited paper to be presented at the Twenty-Seventh Internatinal Conference on Infrared and Millimeter Waves, September 22-26, 2002, San Diego, California, and to be published in the Proceedings.

\author{
Work supported by \\ the U.S. Department of Energy under \\ Contract No. DE-AC03-99ER54463
}




\title{
Applications of New Technology for Production of High Power Millimeter Waves to Magnetic Fusion Research
}

\author{
John Lohr \\ DIII-D National Fusion Facility, General Atomics, P.O. Box 85608, San Diego, California 92186-5608
}

\begin{abstract}
Although research on magnetically confined fusion plasmas has been carried out for a half century, for most of this time control of the temperature, density and current density profiles has been limited and transient. Now, high power long pulse gyrotron systems with excellent reliability are coming on line, which can provide non-inductively driven currents and electron heating leading to higher plasma performance and continuous operation in reactor relevant regimes. The precision of the location at which heating and current drive are applied has also made it possible to suppress certain classes of plasma instabilities. Basic physics of electron cyclotron current drive and heating are understood and these new technological capabilities are being exploited in magnetic confinement devices worldwide.
\end{abstract}

\section{INTRODUCTION}

The electron cyclotron frequency,

$$
\mathrm{f}_{\mathrm{ce}}=2.8 \times 10^{10} \mathrm{~B}(\mathrm{~Hz})
$$

is between about 50 and $90 \mathrm{GHz}$ in present day magnetic fusion devices. In a reactor based on the tokamak, considerations of the physical accessibility to the plasma dictate that heating hardware be located on the low field side of the device. In the case of rf heating and current drive using the electron cyclotron resonance, it is necessary to operate at the second harmonic of the electron cyclotron frequency and in the extraordinary mode in order to obtain the precise localization of absorption at the resonance while avoiding the X-mode cutoff at which the rf waves would be reflected. Therefore, the source frequency will be in the range 100$180 \mathrm{GHz}$. In the past few years, advances in the state of the art have enabled gyrotron oscillators in this range with output powers up to $1 \mathrm{MW}$ to be placed in service. The $\mathrm{rf}$ efficiencies of these tubes have been increased to nearly $50 \%$ using depressed potential collectors. Tubes with multiple output frequencies have been tested. The parallel development of high quality output windows made from artificially grown diamond disks has enabled these gyrotrons to be operated nearly continuously, producing high quality Gaussian rf beams for transmission to the experimental devices.

\section{TECHNOLOGY}

\section{A. Diamond Output Windows}

No single recent development has had a more profound impact on gyrotron performance than the artificially produced diamond disk for output windows. The disks can be grown up to about $2 \mathrm{~mm}$ in thickness with diameters up to about $120 \mathrm{~mm}$. They typically have $\tan (\delta) \leq 5 \times 10^{-5}$ and thermal conductivity four times that of copper permitting edge cooling to be employed. Typically, such windows, passing $1 \mathrm{MW}$ at about $100 \mathrm{GHz}$, absorb about $2 \mathrm{~kW}$ and achieve peak central temperatures of $150^{\circ} \mathrm{C}$ at equilibrium. Although there were some early failures of the brazes to these windows, reliable $\mathrm{Au} / \mathrm{Cu}$ brazes have now been developed.

\section{B. Depressed Collectors}

A quantum jump in the rf production efficiency was provided by the development of the depressed collector geometry. In conventional gyrotrons, the electron gun is biased negatively to about $80 \mathrm{kV}$ and the collector is grounded. The power supply must have regulation of better than $\pm 0.05 \%$ and deliver the full operating current of about $40 \mathrm{~A}$. Efficiencies of $30 \%-40 \%$ are achieved. In the depressed collector geometry, the accelerating voltage is applied between the cathode and the gyrotron body, but, because very little current is intercepted by the body, this highly regulated supply only needs to provide a few tens of mA. The collector is held at ground potential by a supply, which must sink the full current, but which can be poorly regulated. The energy recovery increases the rf efficiency up to about $50 \%$, with additional cost savings resulting from the reduced power supply requirements. Additional efficiency increases are possible in principle if the collector potential depression is done in two stages.

\section{Multi-Frequency Output}

The location at which power is deposited in a magnetic confinement device depends on the intersection of the resonance surface with the rf beam. Advanced applications of rf-driven currents for suppressing instabilities and the natural equilibrium shifts which occur as the plasma beta changes require some flexibility in the power deposition location. Mechanical or electronic steering of the rf beam can accomplish this, but the deposition location can also be changed by changing the gyrotron output frequency. Coaxial gyrotrons have been developed which can be induced to oscillate at 
discrete frequencies ranging over nearly an octave by changing the gyrotron internal resonance condition. Because the output windows are resonant, this requires a large window at the Brewster angle or possibly a windowless design. A simpler two frequency gyrotron was proposed for the cancelled ECH project on JET, which would have used a window resonant at $3 \lambda / 2$ or $2 \lambda / 2$ depending on the operating frequency.

\section{APPLICATIONS}

\section{A. Current Drive}

Asymmetric heating of the electron distribution function by electron cyclotron waves propagating obliquely to the magnetic field generates a current just outside the cold plasma resonance. When driven outside the magnetic axis in the region of large pressure gradient, modest ECCD currents can modify the $j(r)$ profile generated by the neoclassical bootstrap effect to increase plasma performance. The off-axis current drive efficiency remains high at high beta and measured ECCD efficiencies are well within what will be required to maintain advanced tokamak performance.

\section{B. Suppression of MHD Instabilities}

One of the first ECCD experiments was to modify the current density profile to affect the sawtooth instability. It was found that counter current driven in the center of the discharge was effective at driving up $q(0)$ and suppressing sawteeth, while central co-current drive drove $q(0)$ toward unity, with consequent rapid sawteeth. Now, the neoclassical tearing mode, which results from a deficit of current at a rational q surface has also been suppressed by ECCD. Both the $\mathrm{m} / \mathrm{n}=3 / 2$ and the $\mathrm{m} / \mathrm{n}=2 / 1$ tearing modes have been suppressed by ECCD continuously applied precisely at the location of the axis of the magnetic island chain. Suppression of these modes then permitted an increase in plasma beta to be achieved without return of the mode.

\section{Control of the Electron Temperature Profile}

The power output of gyrotrons is a monotonic function of the applied high voltage. This fact has been used to modulate the output of the tubes using a pre-programmed time dependent waveform. This capability has now been extended to simultaneous feedback control of the entire gyrotron complex by the digital plasma control system (PCS) on DIII-D. In initial tests, the control signal, derived from the local $\mathrm{T}_{\mathrm{e}}$ measurement provided by the heterodyne ECE system, was matched to a desired time dependence of the electron temperature at the same location. The modulated rf power caused the measured temperature to track the desired value with excellent fidelity. This capability was then applied to the control of the current penetration early in the discharge. The feedback system provided for the first time a reliable way of determining the electron temperature at a point in the plasma.

\section{Transport Studies}

Modulated ECH provides a well controlled source of energy at arbitrary locations in the plasma. Although the rf power density is low and the heating effects are small, modulation at specific frequencies enables synchronous detection techniques to be used, greatly increasing the signal to noise ratio of the measurements. Modulated waveforms can be square wave, with depth exceeding $90 \%$, or quasi sinusoidal, providing an approximately monochromatic Fourier spectrum for analysis. Following the propagating heat pulse allows different transport models to be tested and in some cases permits the direct measurement of transport coefficients.

\section{CONCLUSIONS}

Major advances in gyrotron technology have enabled many new experiments to be pursued on magnetic confinement devices. In addition to providing continuous off-axis current drive for enhancement of plasma performance, application of rf power at the MW level has demonstrated control of instabilities and has been used as a precision energy source for direct observation of transport phenomena. The reliability is comparable to other heating systems and new capabilities at lower cost per Watt are still being developed.

\section{ACKNOWLEDGMENT}

This work was supported by the US DOE under Contract No. DE-AC03-99ER54463. 